\title{
Erratum
}

\section{Protein expression in experimental malignant glioma varies over time and is altered by radiotherapy treatment}

\section{Wibom, F Pettersson, M Sjostrom, R Henriksson, M Johansson and AT Bergenheim}

British Journal of Cancer (2006) 95, 766. doi:10.1038/sj.bjc.6603269 www.bjcancer.com

(c) 2006 Cancer Research UK

Correction to: British Journal of Cancer (2006) 94, 1853-1863. doi: $10.1038 / 6603190$

Owing to a publishing error, Figure 3 (parts A and B) in the above paper were reproduced incorrectly. The correct complete Figure 3 is shown below.
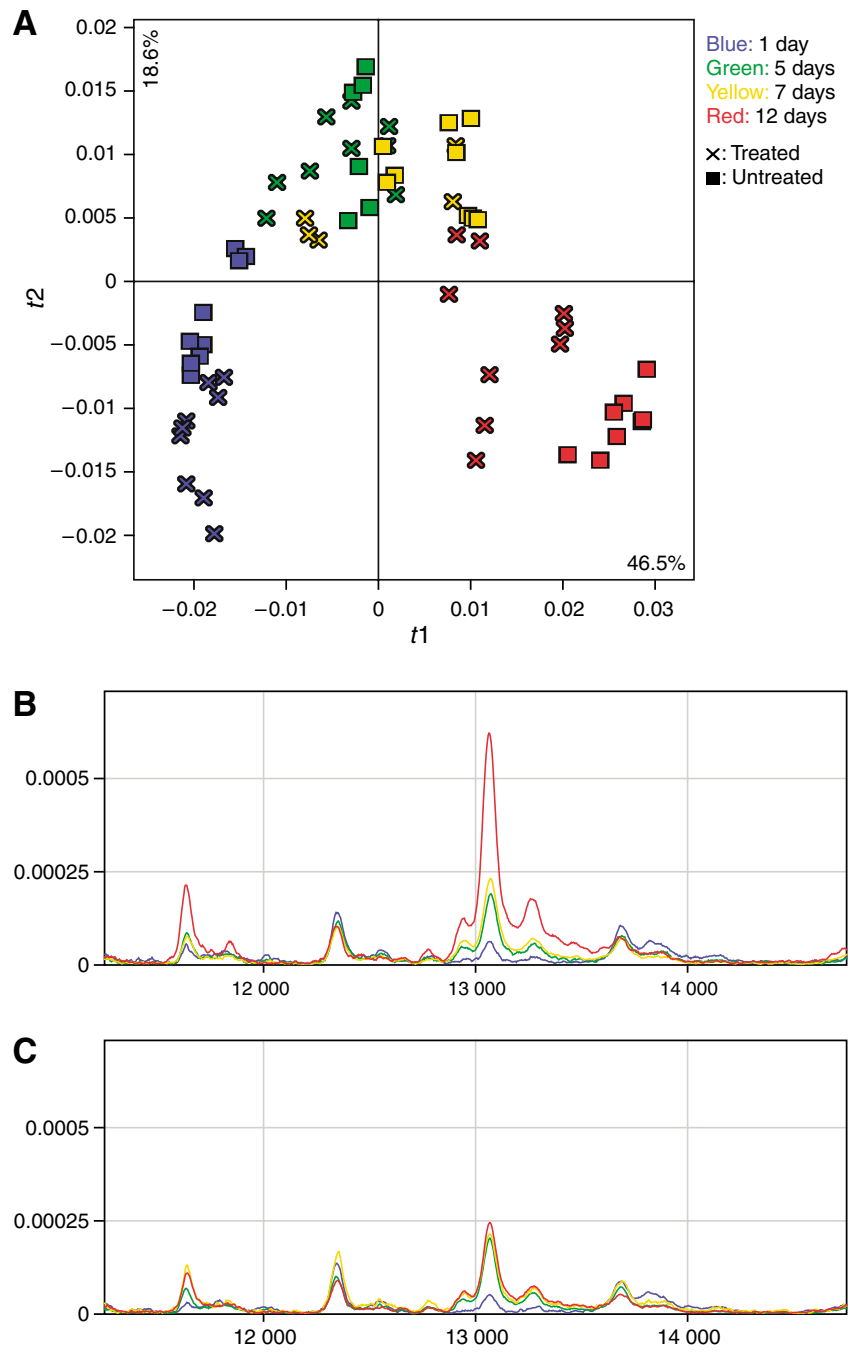

Figure 3 Principal component analysis reveals a time trend in protein expression during tumour progression $(\mathbf{A})$. $R 2 X($ cum $)=0.65$ for the first two components. $x$ and $\mathbf{\square}$ represent treated and untreated samples, respectively, and the different colours represent samples collected at different time points after treatment, as follows: blue $=$ I day; green $=5$ days; yellow $=7$ days; red $=12$ days. $(\mathbf{B})$ and $(\mathbf{C})$ display mean protein profiles within a specific spectral region, derived from untreated and treated samples, respectively. The samples are from the same time points as above and the same colour coding is applied. 